\title{
EFFECTS OF HIGH TEMPERATURE EXPOSURES ON FATIGUE LIFE OF DISK SUPERALLOYS
}

\author{
Tim P. Gabb ${ }^{1}$, Jack Telesman ${ }^{1}$, Pete T. Kantzos ${ }^{2}$, James W. Smith ${ }^{3}$, Paul F. Browning ${ }^{4}$ \\ ${ }^{1}$ NASA Glenn Research Center; 21000 Brookpark Rd.; Cleveland, OH 44135 \\ ${ }^{2}$ Ohio Aerospace Institute; Cedar Point Rd.; Cleveland, OH 44135 \\ ${ }^{3}$ QSS Group, Inc.; 21000 Brookpark Rd.; Cleveland, OH 44135 \\ ${ }^{4}$ Solar Turbines; P.O. Box 85376, MZ P-3 (Turbotec); San Diego, CA 92186
}

Keywords: disk, superalloys, low cycle fatigue, environment

\begin{abstract}
The effects on fatigue life of high temperature exposures simulating service conditions were considered for two disk superalloys. Powder metallurgy processed, supersolvus heat treated Udimet ${ }^{\circledR} 720$ and ME3 fatigue specimens were exposed in air at temperatures of 650 to $704^{\circ} \mathrm{C}$, for times of $100 \mathrm{~h}$ to over $1000 \mathrm{~h}$. They were then tested using conventional fatigue tests at 650 and $704^{\circ} \mathrm{C}$, to determine the effects of exposure on fatigue resistance. Cyclic dwell verification tests were also performed to contrast the effects of intermixed exposures and fatigue cycles. The prior exposures reduced life by up to $70 \%$ and increased the scatter in life, compared to unexposed levels. Cyclic dwell tests reduced lives even more. Fractographic evaluations indicated the failure mode was shifted by the exposures and cyclic dwells from predominantly internal to often surface crack initiations. The increased scatter in life was related to the competition between internal crack initiations at inclusions or large grains producing longer lives, and surface crack initiations at an environmentally affected surface layer producing shorter lives.
\end{abstract}

\section{Introduction}

Low cycle fatigue (LCF) tests conventionally used to characterize the low cycle fatigue resistance of disk superalloys are usually performed at cyclic frequencies of $0.33 \mathrm{~Hz}$ or faster, in the interests of time and cost. However, service conditions for disks in some aerospace and land-based gas turbine engines can produce major cycle periods extending from minutes to hours and days. Over a service life, this can produce total service times exceeding 1,000 hours for aerospace applications and 100,000 hours for land-based applications. The costs of running straincontrolled low cycle fatigue tests in this manner would be prohibitive from both time and cost considerations. However, some aspects of the surface effects of realistic total exposure times could possibly be considered economically.

Time-dependent effects of realistic mission cycles on fatigue resistance can be significant in superalloy disks. Earlier studies have shown that specimen fatigue tests which have dwell times included within each cycle can give lives significantly degraded from test cycles using conventional frequencies of 0.33 to 0.5 hertz (ref. 1-6). However, strain-controlled tests with strain dwells at maximum strain can allow relaxation of maximum cyclic stresses (ref. 7). This reduction in cyclic stress can counterbalance some of the creep and environmental damage produced by service dwell times. Such stress relaxation can be exaggerated over that possible in real disks in service, which have large, elastically constrained volumes. A disk cannot be allowed to creep significantly due to very tight blade, clearance, and rotational constraints within a turbine engine rotor. The majority of a disk is therefore usually not subjected to stress-temperature conditions allowing creep over $0.1-0.2 \%$ during service life. However, the environmental exposures are present over the entire disk surface including "hot spots" on the rim, and their effects on disk life could be important. Extended exposures at elevated temperatures prior to conventional LCF testing has been shown to capture some of the effects of service environment in a cast blade alloy at $871^{\circ} \mathrm{C}$ (ref. 8).

The purpose of this study was to examine the effects of extended exposures simulating service conditions on the fatigue resistance of disk superalloys. Powder metallurgy processed, supersolvus heat treated Udimet 720 (U720) and ME3 superalloy fatigue specimens were exposed in air at several potential maximum application temperatures of 650 to $704^{\circ} \mathrm{C}$ for extended times. They were then tested using conventional fatigue tests at 650 and $704^{\circ} \mathrm{C}$ and compared to more realistic cyclic dwell fatigue tests.

\section{Materials and Procedure}

A Udimet 720 (ref. 9, 10) powder metallurgy disk was obtained courtesy of Solar Turbines from Wyman-Gordon Forgings. Udimet 720 has a nominal composition in weight percent of $2.5 \mathrm{Al}, 0.03 \mathrm{~B}, 0.03 \mathrm{C}, 14.8 \mathrm{Co}, 18 \mathrm{Cr}, 3 \mathrm{Mo}, 5 \mathrm{Ti}, 1.25 \mathrm{~W}, 0.03 \mathrm{Zr}$, bal. $\mathrm{Ni}$. The powder was first atomized in argon. It was then canned, hot isostatically pressed, extruded and isothermally forged using typical conditions for this alloy (ref. 10). The forged pancake was then machined to a disk about $61 \mathrm{~cm}$ diameter and $10 \mathrm{~cm}$ thickness. The disk was heat treated at Wyman-Gordon Forgings, Inc. on a steel tray in a gas-fired furnace. The U720 disk was first given a supersolvus solution heat treatment, then oil quenched. It was then given the conventional aging heat treatment for this alloy. An ME3 (ref. 11, 12) powder metallurgy disk was obtained in a similar manner, through hot compaction, extrusion, and isothermal forging. ME3, also sometimes referred to as Rene' 104 , has a nominal composition in weight percent of $2-5 \mathrm{Al}$, 0.015-0.045B, 0.015-0.1C, 14-23Co, 11-15Cr, 0-2Fe, 0-2Hf, 0$0.1 \mathrm{Mg}, 2.7-5 \mathrm{Mo}, 0.25-3 \mathrm{Nb}, 0-2.5 \mathrm{Re}, 3-6 \mathrm{Ti}, 0.5-4 \mathrm{Ta}, 0-2 \mathrm{~V}, 0.5-$ $3 \mathrm{~W}, 0.015-0.15 \mathrm{Zr}$, bal. Ni. The forged pancake was then machined to a disk of about $18 \mathrm{~cm}$ diameter and $4 \mathrm{~cm}$ thickness. The ME3 disk was first given a supersolvus solution heat treatment and fan air quenched. It was then given an aging heat treatment similar to the U720. 
Specimens were extracted away from all quenched surfaces of the U720 disk, in order to minimize any effects on mechanical properties of oil quenching rate variations at different specimen locations in the disk. Specimens were extracted throughout the smaller, slower quenched ME3 disk. The specimens had a gage diameter of $0.64 \mathrm{~cm}$ and length of $1.9 \mathrm{~cm}$. Many fully machined specimens were first exposed in air as groups of five lying on a tray in a conventional resistance heated furnace. Exposure temperatures of 650 and $704^{\circ} \mathrm{C}$ were used for times of 100 and $1029 \mathrm{~h}$ on U720 specimens. A centerpoint exposure condition of $677^{\circ} \mathrm{C}$ for $510 \mathrm{~h}$ was also included. Only a single exposure condition at $704^{\circ} \mathrm{C} / 439 \mathrm{~h}$ was used for ME3 specimens.

Fatigue tests were performed at $650^{\circ} \mathrm{C}$ on $\mathrm{U} 720$ and $704^{\circ} \mathrm{C}$ for ME3 in closed-loop servo-hydraulic testing machines using induction heating and axial extensometers. The strain vs. time waveforms of baseline and verification fatigue tests are compared in Fig. 1. Most baseline fatigue tests were performed in two stages to reduce total testing time. First, the test was conducted in strain control conditions using a triangular waveform to a total strain range of $0.7 \%$ and strain ratio $\mathrm{R}_{\varepsilon}=\varepsilon_{\min } / \varepsilon_{\max }=0$, with a frequency of $0.33 \mathrm{~Hz}$. After cycling for 24 hours, tests were continued to failure in load control conditions using a triangular waveform to achieve the same stabilized maximum and minimum loads as before, at a frequency of 10 hertz. Verification cyclic dwell fatigue tests were performed with strain controlled throughout the test using a triangular waveform with the same total strain range and strain ratio, but using a load cycle taking 20 seconds followed by a dwell at 0 strain for 40 seconds. The dwell was performed at 0 strain to prevent cumulative relaxation of the maximum cyclic stress during the dwells. This gave a total cyclic dwell period of 1 minute per cycle. All tests were continued until failure.

Fractographic evaluations were performed on all specimens after failure to determine the crack initiation sites. Metallographic sections were prepared from one representative specimen for each exposure and testing condition. The sections were taken from the gage sections and oriented normal to the loading axis. Grain sizes were determined from selected specimens according to ASTM E112 linear intercept procedures using circular grid overlays.

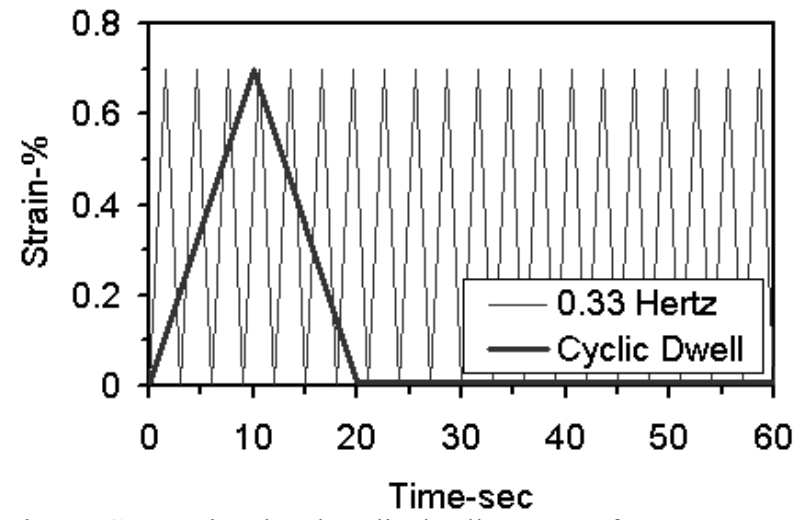

Fig. 1. Conventional and cyclic dwell test waveforms.

\section{Results and Discussion}

Starting Microstructures

The typical microstructures of untested specimens are shown in Fig. 2. U720 specimens had a coarse grain size of ASTM 6.0 (45 $\mu \mathrm{m})$ due to the supersolvus heat treatment. ME3 specimens had a slightly finer grain size of ASTM $7.1(31 \mu \mathrm{m})$.

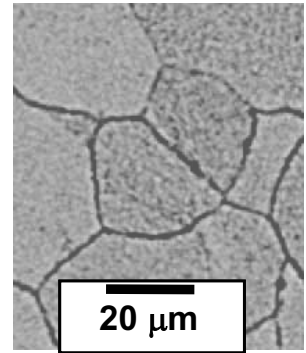

a.

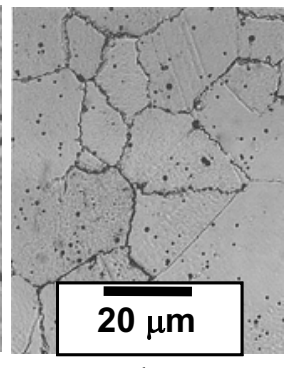

b.
Fig. 2. Typical microstructures of: a. U720 and b. ME3.

Initial Assessments of Exposure Effects on U720 Fatigue Life Fatigue life of U720 is shown versus estimated cumulative probability to compare the effects of various exposures on subsequent LCF life in Fig. 3. Lives of exposed specimens were invariably lower than unexposed specimens, reducing mean life by up to $70 \%$. It can also be seen that exposed specimens had lower slopes on the probability plot, indicating more scatter and larger standard deviations than for unexposed specimens. Plots of exposed specimen lives versus their exposure temperatures and times are shown in Fig. 4, with no strong trends apparent due to the scatter in life responses.
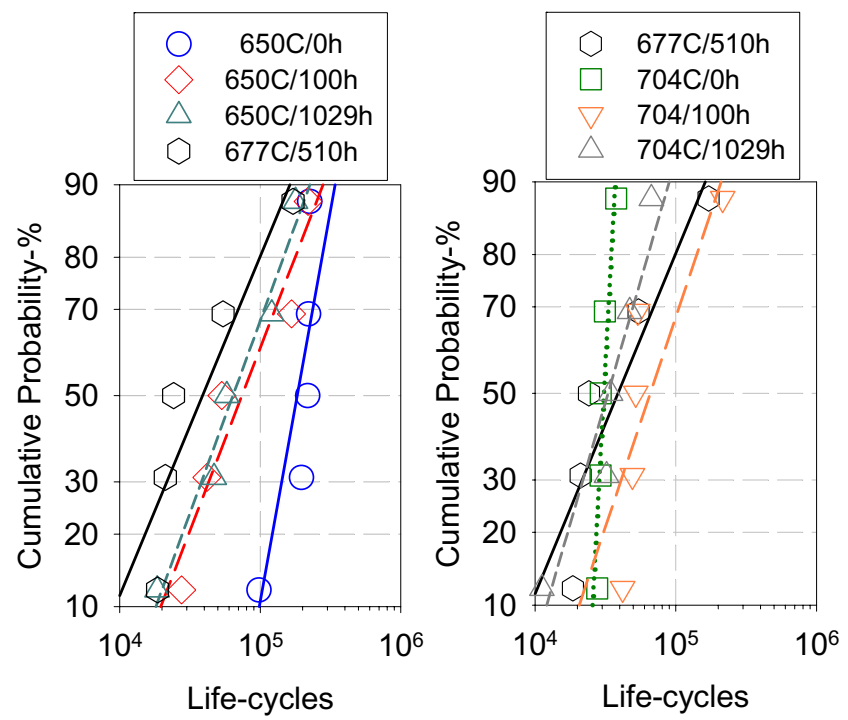

Fig. 3. Comparison of fatigue lives at $650^{\circ} \mathrm{C}$ and a total strain range of $0.7 \%$ for $\mathrm{U} 720$ with prior exposures. 


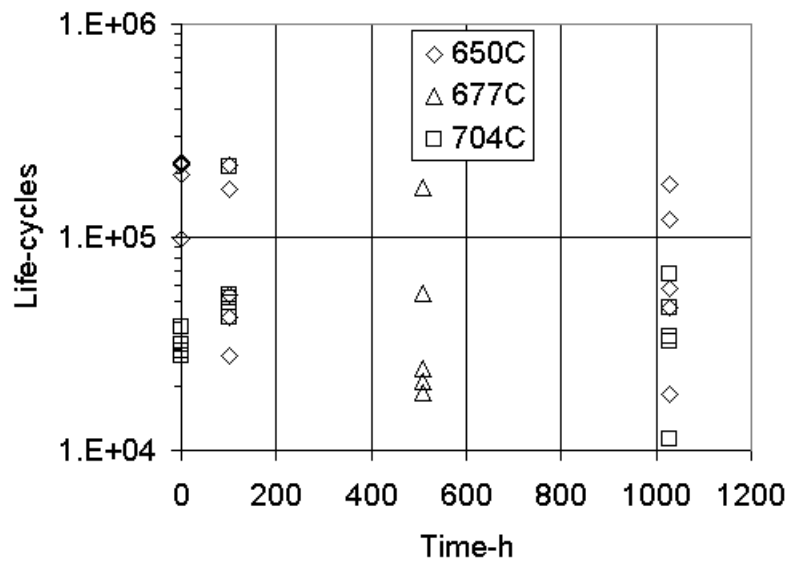

Fig. 4. Fatigue lives at $650^{\circ} \mathrm{C}$ and a total strain range of $0.7 \%$ for U720 with prior exposures for U720 versus exposure temperature and time.

A linear regression model was generated using forward step-wise regression with the factors exposure temperature, $\log$ (time), and their interaction to model fatigue life. The resulting relationship obtained had poor correlation and only included temperature:

$$
\log (\text { life })=4.7653-0.1852 * \mathrm{~T}^{\prime},
$$

where $T^{\prime}=($ temperature-677)/27. This gave a low adjusted correlation coefficient $\mathrm{R}^{2}$ adj $=0.373$ and root mean square (rms) error of 0.212 .
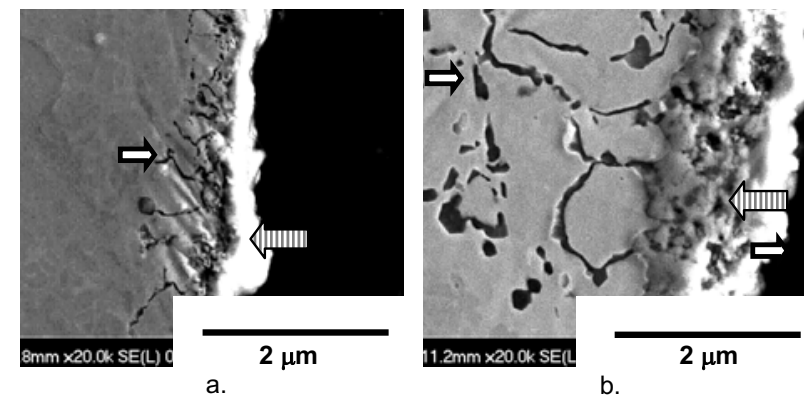

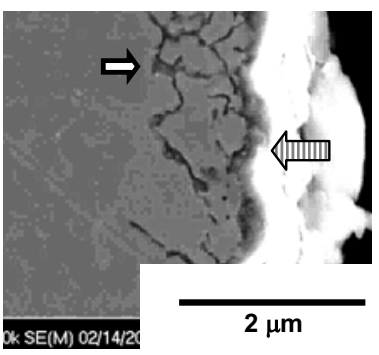

c.

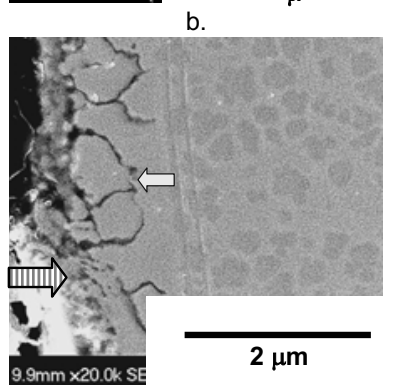

d.
Fig. 5. Oxidized surface layers for U720 tests: a. pre-exposed $650^{\circ} \mathrm{C} / 100$ h, b. pre-exposed $704^{\circ} \mathrm{C} / 1029$ h, c. $704^{\circ} \mathrm{C}, 0.33$ hertz, d. $650^{\circ} \mathrm{C}$, cyclic dwell. Hatched arrows indicate continuous layer of $\mathrm{Ni}$, Co-rich oxide; open arrows indicate fingers of $\mathrm{Al}-$ rich oxide.

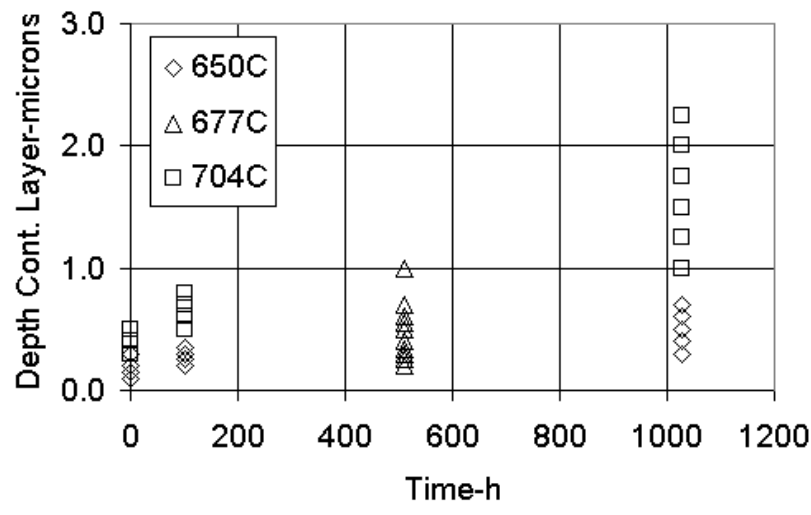

a.

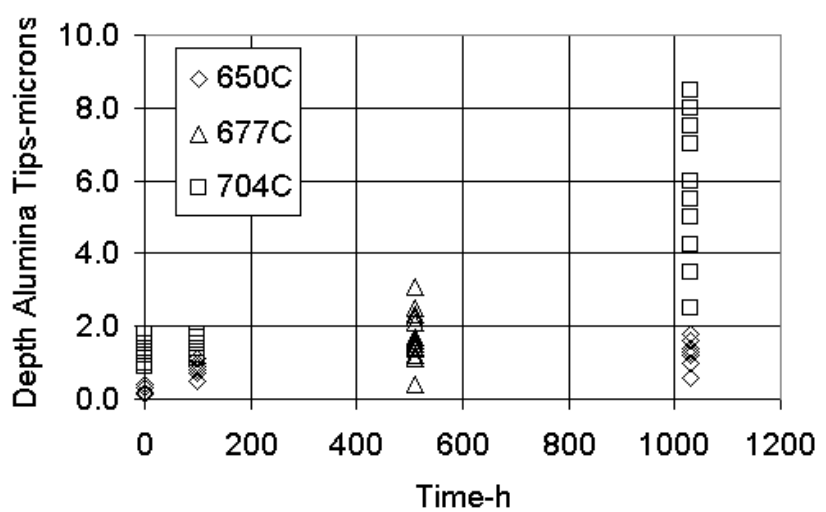

b.

Fig. 6. Depths versus exposure temperature and time in U720 for: a. continuous $\mathrm{Ni}, \mathrm{Co}$ oxide layer and $\mathrm{b}$. Al oxide finger tips.

Transverse metallographic sections were prepared from representative failed specimens to compare the effects of surface exposures. As shown in Fig. 5, an oxidized continuous surface layer predominantly made up of nickel and cobalt oxide can be clearly seen in the exposed specimens. An additional zone with branched fingers of attack, rich in aluminum oxide, extended further in. $\gamma^{\prime}$ precipitates were absent in the superalloy adjacent to the aluminum oxide fingers. The depth of the continuous $\mathrm{Ni}$,Co oxide layer (DCL), and the depth to the aluminum oxide tips (DAT) tended to increase with exposure temperature, and exposure time, Fig. 6. Variability in depths also increased with temperature and time. Multiple linear regression was therefore performed using the cube root of oxide depths, in order to equalize the variability of depth responses across all conditions. The resulting regression equations both showed strong dependencies of oxide depth on exposure temperature and time:

$\mathrm{DCL}^{1 / 3}=0.8160+0.1283^{*} \mathrm{~T}^{\prime}+0.0781 * \mathrm{LT}^{\prime} ; \mathrm{R}_{\text {adj }}{ }^{2}=0.776$

$\mathrm{DAT}^{1 / 3}=1.1691+0.2283^{*} \mathrm{~T}^{\prime}+0.1265^{*} \mathrm{LT}^{\prime} ; \mathrm{R}_{\mathrm{adj}}^{2}=0.727$

$\mathrm{T}^{\prime}=\left(\right.$ temperature-677) $/ 27$ and $\mathrm{LT}^{\prime}=(\log ($ time $\left.)-2.2052) / 8.0720\right)$.

Simple linear regressions of $\log ($ life $)$ with the depth of the continuous Ni,Co oxide layer (DCL), and the depth to the 
aluminum oxide tips (DAT) were also performed. Due to the strong cross correlation between DCL and DAT, these variables were assessed separately. As shown in the resulting regressions equations $4-5$, DAT was a slightly better predictor of life than DCL.

$\log ($ life $)=4.7181-0.2845 *\left(\mathrm{DCL}^{1 / 3}-0.83\right) / 0.31 ; \mathrm{R}_{\text {add }}^{2}=0.339$
$\log ($ life $)=4.7119-0.3488 *\left(\mathrm{DAT}^{1 / 3}-1.195\right) / 0.565 ; \mathrm{R}^{2}{ }_{\text {adj }}=0.535$

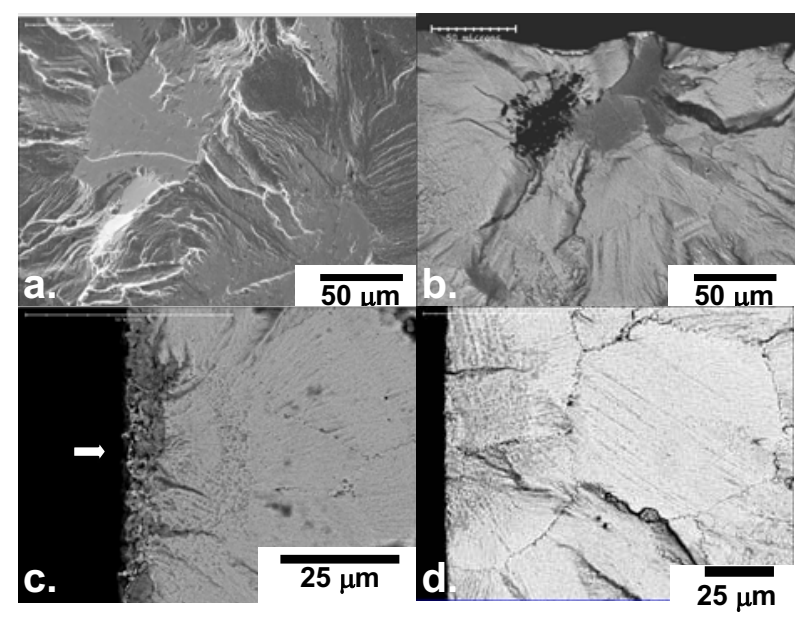

Fig 7. Typical failure initiation sites for $\mathrm{U} 720$ tests: a. $650^{\circ} \mathrm{C} / 0.33$ hertz, grain failure, b. $650^{\circ} \mathrm{C} / 0.33$ hertz, inclusion failure, c. pre-exposed $704^{\circ} \mathrm{C} / 1029 \mathrm{~h}$, surface oxide failure, and d. $650 \mathrm{C}^{\circ}$ cyclic dwell, surface oxide failure.

Typical fatigue failure sites in these tests are compared in Fig. 7. Unexposed U720 specimens failed from cracks initiating internally at large grains or at non-metallic inclusions. The large grains appeared to start cracks by failing on a single flat plane or "facet", presumably due to concentrated slip along a single slip band (ref. 7). The non-metallic inclusions were predominantly composed of $\mathrm{Al}_{2} \mathrm{O}_{3}$, and were presumably introduced during the powder production and handling processes before consolidation (ref. 6). Exposed specimens sometimes failed from cracks initiating internally at these above sites, but more often failed from cracks initiating at an environment-affected surface layer, especially for long exposure times. These cracks initiated and grew in a transgranular mode normal to the loading axis.

These competing failure modes clearly accounted for the wide scatter in life of exposed specimens, as illustrated in the probability plot of Fig. 8. Specimens failing from internal cracks initiating at grain facets or inclusions had relatively long lives for each condition, comparable to unexposed lives. Specimens failing from cracks at the surface layer had relatively short lives and could be combined into one population. A non-linear regression model was generated using forward step-wise regression of the factors exposure temperature, $\log$ (time), depth of the failure initiation point categorized as 0 for surface and 1 for internal initiations, and their interactive terms to model fatigue life. Some cross-correlations of exposure time with depth of the failure initiation point, and exposure temperature with depth were present, which prevented inclusion of all terms in the model. This indicated that increased exposure time and temperature increased the likelihood of promoting surface-initiated failures. However, depth of the failure initiation was found to be a far better predictor of life. The resulting relationship obtained was therefore only a function of depth, but it gave a much improved $\mathrm{R}^{2}$ adj of 0.628 and rms error of 0.236 compared to the previous temperature-based regression:

$$
\log (\text { life })=4.5798 \text { if depth }=\text { surface, }
$$$$
\log (\text { life })=5.2108 \text { if depth }=\text { internal. }
$$

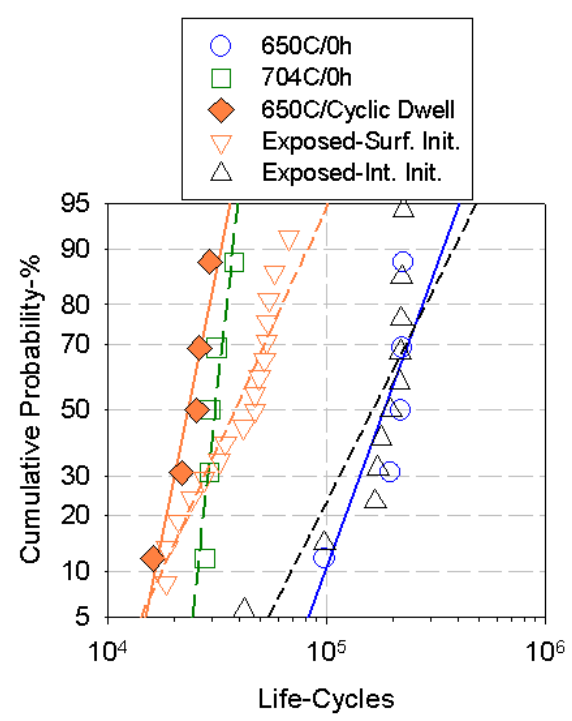

Fig. 8. Pre-exposed and cyclic dwell fatigue lives for U720 versus failure initiation sites.

In order to test the validity of using pre-exposures at the same or elevated temperatures to capture some effects of service exposures, two additional groups of tests were performed. Conventional cyclic tests were performed at $704^{\circ} \mathrm{C}$ without prior exposures, in order to understand the effects of higher test temperature alone on inherent fatigue life. A cyclic dwell test was also performed at $650^{\circ} \mathrm{C}$ to directly compare the effects of prior exposures to the effects of more realistic mixing of cyclic loading and exposures. The period of the cyclic dwell cycle was selected by simply dividing the longest exposure time at $650^{\circ} \mathrm{C}$ of $1029 \mathrm{~h}$ by the observed subsequent log mean life of 64,021 cycles. This gave an overall cycle period of $1 \mathrm{~min}$, as shown in Fig. 1. Within each cycle, a strain cycle of $0.7 \%$ with $\mathrm{R}_{\varepsilon}=0$ was first applied to reproduce that of the conventional LCF tests. A dwell at 0 strain was then applied to introduce exposure effects.

These lives are compared to the previous results in the probability curves of Fig. 8. The unexposed tests at $704^{\circ} \mathrm{C} / 0.33$ hertz produced lives of 27,730 to 37,782 cycles, while the cyclic dwell tests at $650^{\circ} \mathrm{C}$ produced lives of 16,054 to 29,204 cycles. The cyclic dwell lives were therefore even lower than those of exposed specimens having surface initiated failures. Fractographic evaluations indicated the $704^{\circ} \mathrm{C}$ tests and cyclic dwell tests specimens all had surface initiated failures from the environmentaffected surface layers, included in Fig. 6 . So while preexposures did encourage surface initiated failures from oxide layers, pre-exposures up to $704^{\circ} \mathrm{C} / 1029 \mathrm{~h}$ did not appear to capture all effects on life of more service-realistic cyclic dwell tests, due to potential fatigue-dwell interactions. Measurements of the oxide layers indicated a continuous $\mathrm{Ni}, \mathrm{Co}$-oxide layer depth 
(DCL) of $0.28 \mu \mathrm{m}$ and Al-rich oxide finger tip depth (DAT) of $1.06 \mu \mathrm{m}$. The DCL was very close to that predicted by the preexposure based regression equation 2 , which gave $0.33 \mu \mathrm{m}$.

However, the DAT was greater than that predicted by the preexposure-based regression equation 3 , which gave $0.86 \mu \mathrm{m}$. This suggested that the lower lives of cyclic dwell tests could be associated with enhanced surface oxidation.

\section{ME3 Fatigue Test Results}

Additional fatigue tests were performed on disk alloy ME3 to understand the causes of low lives in cyclic dwell fatigue tests and possible relationships to prior exposure effects. Cyclic dwell tests were first performed on ME3 at $704^{\circ} \mathrm{C}$, giving a log mean life of 26,362 cycles and test duration of $439 \mathrm{~h}$ at the same total strain conditions of $0.70 \%$, (Fig. 1). This test duration time was then used for the prior exposure condition. This allowed clear comparisons at constant exposure temperature and time. The contribution of environmental attack was isolated by comparing prior exposures of $704^{\circ} \mathrm{C} / 439 \mathrm{~h}$ in air versus vacuum. Prior exposure in air reduced fatigue life about $50 \%$ from unexposed levels (Fig. 9), and usually induced surface oxide-initiated failures. Prior exposures in vacuum did not significantly reduce subsequent mean fatigue life from unexposed levels, indicating the air environment was strongly contributing to the damage. Long exposures could also be detrimental by reducing beneficial compressive residual stresses produced near the specimen surface during machining. These effects were evaluated by electropolishing away the surface layer on several specimens before conventional fatigue testing. The fatigue lives of these specimens showed more scatter than unpolished specimens, but fatigue life was not consistently reduced by the electro-polishing. This indicated relaxation of beneficial compressive residual stresses was not strongly driving the life reductions due to exposure. Cyclic dwell testing was again most damaging, reducing mean fatigue life about $90 \%$ in comparison to unexposed, conventional fatigue test life. Therefore, the mixing of fatigue and environment damage in each cycle was an important consideration in determining service exposure effects on life.

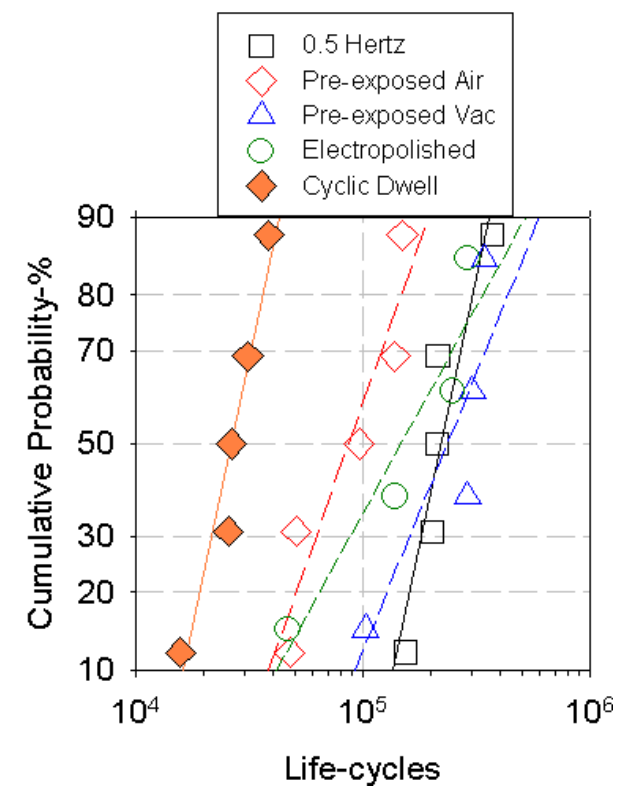

Fig. 9. Fatigue lives for ME3 at $704^{\circ} \mathrm{C}$ for different conditions.
Failure analyses results reflected those for U720. Conventional 0.33 hertz tests on unexposed as-machined and electropolished specimens typically failed from cracks initiated at internal grain facets or ceramic inclusions. Specimens pre-exposed in vacuum also failed from these features, however specimens pre-exposed in air usually failed from cracks initiating at surface oxide layers. Cyclic dwell test specimens invariably failed form these surface oxide cracks.

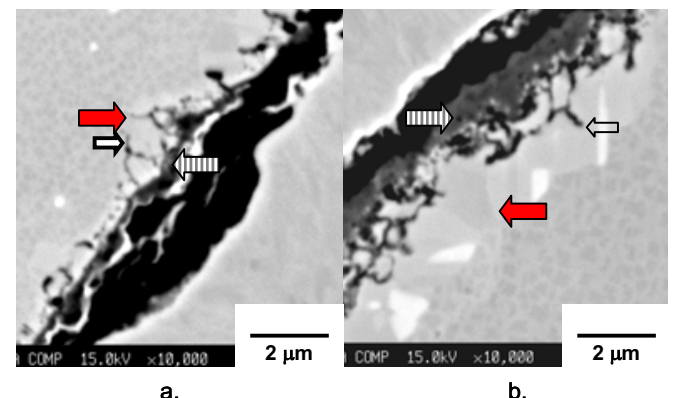

Fig. 10. Comparison of oxide layers in ME3 tests: a. preexposed $704^{\circ} \mathrm{C} / 439 \mathrm{~h}$, b. $704^{\circ} \mathrm{C}$, cyclic dwell, total test time 439 h. Hatched arrows indicate continuous layer of $\mathrm{Ni}$, Co-rich oxide; open arrows indicate fingers of Al-rich oxide. Filled arrows indicate $\gamma^{\prime}$ depleted superalloy.

The oxide layers were examined in metallographic sections prepared normal to the loading axis of these specimens as before. Specimens without pre-exposure or pre-exposure in vacuum had similar, very thin surface oxide layers of less than $0.5 \mu \mathrm{m}$. Specimens pre-exposed in air or tested with cyclic dwells for the same total time at temperature are compared in Fig. 10. Note that this clear comparison of pre-exposed and cyclic dwell specimens with the same total time at temperature was not possible for the U720 tests. The ME3 specimen micrographs shown represent the greatest depths of attack observed in each metallographic section. Such locations would be expected to represent preferred fatigue crack initiation sites. In both cases, a continuous outer layer of $\mathrm{Ni}$, Co-rich oxide is present, along with underlying Al-rich oxide fingers. Continuous layer, finger tip, and $\gamma^{\prime}$ depletion depths are all increased by roughly $100 \%$ for the cyclic dwell specimen over those of the pre-exposed specimen. This appears consistent with the lower lives of the cyclic dwell specimens over specimens preexposed for the same temperature and time, and confirms the prior indications for U720. Cyclic dwells produce greater depths of attack for the same temperature and time, apparently due to some sort of stress-enhanced diffusion of the oxidizing elements to the exposed surface. Additional cyclic tests varying stress profiles would be necessary to help understand the stress and time dependencies of this surface oxidation process, and to relate it to more complicated engine service cycles.

\section{Summary of Results and Conclusions}

In summary, prior exposures significantly affected fatigue life. The exposures reduced life and increased the scatter in life, compared to unexposed levels. Fractographic evaluations indicated the failure mode was shifted in many cases by the exposures from internal to surface crack initiations. Experiments using vacuum exposures showed microstructural overaging was not driving the reductions in life. Electropolishing experiments 
showed that relaxation of beneficial compressive residual stresses from machining also did not drive the life reductions. Instead, the air environment was causing the reductions in life. The increased scatter in life was related to the competition between internal crack initiations at inclusions or large grains producing longer lives, and surface crack initiations at environment-affected surface layers producing shorter lives. Surface crack initiated failures and associated shorter lives did approach those of more servicerealistic cyclic dwell fatigue tests, as well as in tests at higher temperatures. However, a fatigue-environment interaction produced lower lives in the cyclic dwell tests than for pre-exposed specimens, for the same total time at temperature. The fatigueenvironment interaction produced greater depths of an outer continuous layer of $\mathrm{Ni}$, Co-rich oxide and underlying Al-rich oxide fingers, related to a stress-assisted oxidation process.

It can be concluded that prior exposures can be used to help approximate some aspects of service exposure effects. The exposures accomplish this by shifting to some degree the probable failure initiation site from internal sites to the environmentaffected surface layer, as observed in cyclic dwell tests performed to simulate service conditions. This produces a significantly lower, more service-realistic life than for internally initiated failures often observed in conventional 0.33 hertz LCF tests. However, some combination of higher temperature and longer exposure time appears necessary to give low lives comparable to service exposures as simulated in the cyclic dwell tests. In order to use this approach to approximate service effects on life, it would be necessary to screen pre-exposed versus cyclic dwell tests, then select sufficiently long exposure times which can induce this surface failure initiation mode and the low cyclic dwell lives. It would then still be necessary to segregate the resulting lives of pre-exposed specimens according to failure initiation site. The lives corresponding to surface-initiated failures could be developed to reasonably approximate cycle dwell and service lives. Lives corresponding to internally initiated failures should be considered separately. These internally initiated failures could in some cases approximate exposure effects associated with microstructural instabilities and defects, rather than environmental effects.

Service conditions could also entail more hostile environments than air at 1 atmosphere as used here. Different locations on compressor disks could be subjected to air at variously elevated pressures and temperatures. Locations on turbine disks could be subjected to high pressure air or combustion products at elevated temperatures. Salt deposits promoting hot corrosion could also be present. These environments would affect the environmental attack processes, and would also need to be considered in determining service effects on fatigue life.

\section{Acknowledgments}

The authors would like to acknowledge Mike Fitzpatrick of Solar Turbines and Arun Watwe of Wyman-Gordon Forgings for overseeing Udimet 720 material processing. Support of the Department of Energy, NASA Ultrasafe, and NASA Ultra Efficient Engine Technologies programs are also acknowledged.

\section{References}

1. S. S. Manson, G. R. Halford, M. H. Hirschberg, "CreepFatigue Analysis by Strain Range Partitioning”, First Symposium on Design for Elevated Temperature Environment, S. Y. Zamrik, ed., American Society for
Mechanical Engineering, New York, NY, 1971, pp. 1224.

2. J. R. Ellis, E. P. Esztergar, "Considerations of CreepFatigue Interaction in Design Analysis", Symposium on Design for Elevated Temperature Environments, American Society for Mechanical Engineers, New York N.Y., 1971, pp. 29-43.

3. G. R. Halford, "Low-CycleThermal Fatigue", Thermal

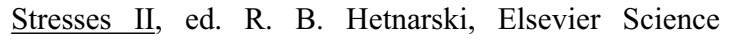
Publishers BV, The Netherlands, 1987, pp. 330-428.

4. G. Cailletaud, D. Nouailhas, C. Escaravage, J. Heliot, S. Kang, J. Grattier, C. Levaillant, M. Mottot, J. Tortel, "A Review of Creep Fatigue Life Prediction Methods", 7th International Conference on Structural Mechanics in Reactor Technology-SMIRT 7", Chicago, IL, 1983, pp. 122-132.

$5 . \quad$ B. A. Cowles, K. L. Sims, J. R. Warren, R. V. Miner, Trans. ASME, 1980, V. 102, pp. 356-363.

6. M. F. Day, G. B. Thomas, "Analysis of the Low-Cycle Fatigue Behavior of Two Ni-Cr-Base Alloys", Fatigue Fract. Engng. Mater. Struct., V. 8, 1985, pp. 33-48.

7. J. M. Hyzak, "The Effect of Defects on the Fatigue Initiation Process in Two P/M Syperalloys", Technical Report AFWAL-TR-80-4063, Air Force Wright Aeronautical Laboratories, Wright-Patterson Air Force Base, Ohio, 1980.

8. S. D. Antolovich, P. Domas, J. L. Strudel, "Low Cycle Fatigue of Rene' 80 as Affected by Prior Exposure", Met. Trans. A, V. 10A, 1979, pp. 1859-1868.

9. W. J. Boesch, U.S. Patent No. 4,093,476, 1978.

10. D. U. Furrer, "A Review of U720LI Alloy and Process Development", in Materials Design Approaches and Experiences, ed. J.-C. Zhao, M. Fahrmann, T. M. Pollock, The Minerals, Metals, and Materials Society, Warrendale, PA, 2001.

11. D. P. Mourer, et al, European Patent EP 1,195,446 A1, 2002.

12. T. P. Gabb, J. Telesman, P. T. Kantzos, K. O'Connor, "Characterization of the Temperature Capabilities of Advanced Disk Alloy ME3”, NASA TM-2002-211796, National Aeronautics and Space Administration, Washington, D.C., 2002. 